\title{
Effects of Azadirachta indica leaf aqeous extract on the antioxidant enzymes in paracetamol-induced hepatotoxicity in Wistar rats
}

\author{
Emmanuel Ikechukwu NWOBODO ${ }^{1 *}$, Dennis C. NWOSU², \\ Sylvester Ogbonna OGBODO ${ }^{3}$, Francis Onukwube UGWUENE ${ }^{4}$, Augustine C. IHIM $^{5}$, \\ Nnenna ONUABUCHI ANI ${ }^{6}$, John Kennedy NNODIM ${ }^{2}$ and OKWUDILI ANI ${ }^{5}$
}

\author{
${ }^{I}$ Department of Biochemistry, Faculty of Natural Sciences, \\ Chukwuemeka Odimegwu Ojukwu University, Uli, Anambra State, Nigeria. \\ ${ }^{2}$ Department of Medical Laboratory Science, Imo State University, Owerri, Imo State, Nigeria. \\ ${ }^{3}$ Department of Medical Biochemistry, Faculty of Basic Medical Sciences, College of Medicine, \\ Enugu State University of Science and Technology, Enugu, Nigeria. \\ ${ }^{4}$ Department of Medical Laboratory Science, Faculty of Basic Medical Sciences, College of \\ Medicine, Enugu State University of Science and Technology, Enugu, Nigeria. \\ ${ }^{5}$ Department of Medical Laboratory Science, Nnamdi Azikiwe University, \\ Awka, Anambra State, Nigeria. \\ ${ }^{6}$ Department of Biochemistry, Nnamdi Azikiwe University, Awka, Anambra State, Nigeria. \\ "Corresponding author; E-mail: emmanwobodo779@yahoo.com
}

\begin{abstract}
Azadirachta indica, reported to be antioxidative, is hepatoprotective. This study evaluates the effect of A. indica leaf aqueous extract on antioxidant enzymes (glutathione peroxidase (GPx), superoxide dismutase (SOD) in paracetamol induced hepatotoxicity in Wister rats. Twenty four rats, in four groups, each containing six rats were used. Group A was given normal saline, group B paracetamol ( $800 \mathrm{mg} / \mathrm{kg}$ body weight $)$ and groups C and D paracetamol and graded doses of the extract $(400 \mathrm{mg}$ and $800 \mathrm{mg} / \mathrm{kg}$ body weight respectively). The animals were weighed before and after experiment. Plasma liver enzymes (alanine transaminase (ALT), aspartate transaminase (AST) and alkaline phosphatases (ALP), plasma and liver homogenate malondialdehyde (MDA), GPx and SOD were estimated. Results showed significant weight increase $(\mathrm{P}<0.05)$ in A and D and weight loss in B. ALT, AST and ALP were significantly increased in B compared with $\mathrm{A}$ while $\mathrm{C}$ and $\mathrm{D}$ were decreased compared wth $\mathrm{B}$. Plasma and homogenate MDA were increased while GPx and SOD were decreased in B compared wth A. Groups C and D MDA were decreased with increased GPx and SOD compared wth B. The extract could be a potent antidote to paracetamol induced hepatotoxicity as indicated by the increased GPx and SOD in C and D.
\end{abstract}

(C) 2018 International Formulae Group. All rights reserved.

Keywords: Azadirachta indica, hepatoxicity, paracetamol, malondialdehyde, antioxidant enzymes.

\section{INTRODUCTION}

Azadirachta Indica (Neem) is well known in India and her neighbouring countries for more than two centuries as one of the versatile medicinal plants having a wide spectrum of biologicalactivities (Kausik et al., 2002). It is also widely grown in Africa (David et al., 2010). It has been known, as a 
result of its phytochemical constituents, to possess antiinflammatory, antipyretic, antimicrobial, antidiabetic, and diverse pharmacological properties (El-Hawary, et al., 2013; Prashanth and Krishnaiah, 2014).

Hepatocellular activity of aqueous leaf extract of $A$. indica has been demonstrated by the findings that it offers protection against paracetamol induced liver necrosis in rats (Bhanwra et al., 2000). Transaminases and alkaline phosphatase are plasma enzymes of hepatic origin which make it possible to explore the state of liver (Suja et al., 2004). A significant rise in the serum concentration of these enzymes is a sign of hepatic intoxication (Kpemissi 2015). The elevated levels of serum aspartate aminotransferase (AST), alanine aminotransferase (ALT), and gammaglutamyl transpeptidase (GGT), indicative of liver damage, were found to be significantly reduced on administration of this aqueous leaf extract (Kausik et al., 2002). The levels of ALT and AST have long been used to assess the functions of liver. Increased plasma levels of both ALT and AST have been linked to tissue toxicity (Adeyemi and Akanji, 2011). ROS have been proven to be associated with paracetamol-induced hepatotoxicity (Momoh, et al., 2015) .

The chemical constituents found in the leaves of A. indica (neem) are nimbin, 6desacetylnimbinene, nimbandiol, nimbolide, ascorbic acid, n-hexacosanol and amino acid, 7-sdesacetyl-7- benzoylazadiradione,7sdesacetyl-7-benzoylgedunin, 17-hydroxy azadiradione and nimbiol (Kokate et al., 2010; Hossain et al., 2013). Toxic doses of paracetamol cause a serious potentially fatal hepatotoxicity (Adeshina et al. 2011). It causes typical centrilobular necrosis in the liver, described in detail in 2013 by Mitchell and his colleagues. This could be as a result of its potential to induce oxidative stress. Oxidative stress results from the imbalance between oxidants and antioxidants in the favour of the formers (Vemo 2017). It has been reported that ROS are known to play an important role in liver disease pathology and progression (Vitaglione, 2004). Increased ROS production lowers cellular antioxidant levels and enhances the oxidative stress in many tissues, especially the liver (Hye-Lin Ha, et al., 2010). There have been found many mechanisms contributing to the cell death impairment of mitochondrial respiration, induction of oxidative stress and lipoperoxidation (Roušar et al., 2009). Oxidative stress is an imbalance between the systemic manifestation of reactive oxygen species (ROS) and a biological systems ability to readily detoxify the reactive intermediates or to repair the resulting damage. ROS are highly reactive and in the absence of any protective mechanism can disrupt normal metabolism through oxidative damage to lipids, protein and nucleic acids. Disturbances in the normal redox state of cells can cause toxic effects through the production of peroxides and free radicals that damage all components of cell including proteins, lipids and DNA. Oxidative stress from oxidative metabolism causes base damage as well as strand-breaks in DNA. Base damage is mostly indirect and caused by reactive oxygen species generated, e g. superoxide radical $\left(\mathrm{O}_{2}{ }^{-}\right)$, hydroxyl radical $\left(\mathrm{OH}^{-}\right)$and hydrogen peroxide $\left(\mathrm{H}_{2} \mathrm{O}_{2}\right)$ (Chandra et al., 2015).

The oxidative effect of these reactive oxygen species can be reduced or obliterated by enzymatic antioxidants, such as superoxide dismutases (SOD) and glutathione peroxidase, and non enzymatic antioxidants. Antioxidant defences are classified as three groups namely, (i) the preventive antioxidants, such as superoxide dismutase (SOD), glutathione peroxidase (GPx) and metal chelating proteins; (ii) the radical-scavenging antioxidant, such as vitamins $\mathrm{C}$ and $\mathrm{E}$, and (iii) the repairs and de novo enzymes, such as lipase and DNA repair enzymes (Willcox et al., 2004).

At the center of this new focus on oxidative stress is the transcription factor called nuclear factor (erythroid-derived 2)-like 2, or Nrf2. Nrf2 is referred to as the "master regulator" of the antioxidant response, 
modulating the expression of hundreds of genes, including not only the familiar antioxidant enzymes, but large numbers of genes that control seemingly disparate processes. Nrf2 on activation modulates the expression levels of hundreds of gene products that can affect oxidative stress and the related pathophysiological states. Thus, the dysregulation of Nrf2-regulated genes provides a logical explanation for the connections, both direct and indirect, between observable oxidative stress and perhaps 200 human diseases involving these various physiological processes, each reflecting a network involving many gene products (Hybertson et al., 2011).

Superoxide dismutases (SOD) are antioxidant enzymes that protect tissues from oxygen toxicity caused by superoxide $\left(\mathrm{O}_{2}\right)$ free radicals. It catalyzes the breakdown of the superoxide anion into oxygen and hydrogen peroxide (Zelko et al., 2002). These are a class of ubiquitous and closely related enzymes that function to efficiently catalyze the dismutation of superoxide anions. SOD enzymes are present in almost all aerobic cells and extracellular fluids (Johnson and Giulivi, 2005). Glutathione peroxidase is an enzyme containing four selenium-cofactors that catalyzes the breakdown of hydrogen peroxide and organic hydroperoxides (Rhee et al., 2005).

MDA is one of the final products of polyunsaturated fatty acids peroxidation in the cells. Increase in free radicals causes overproduction of MDA. Lipid peroxidation is a well established

mechanism of cellular injury and is used as an indicator of oxidative stress in cells and tissues (Ehiaghe, 2015). It is known that the quantity of MDA is an intensity index of peroxidation process of polyunsaturated fatty acids (PUFAs) containetablead in food (Niedworok and Bielaszka, 2007). Malondialdehyde level is commonly known as a marker of oxidative stress and the antioxidant status (Fakher et al., 2007).
MATERIALS AND METHODS

Plant materials

Procurement

Fresh matured leaves of A. indica were collected from a local neem tree at Ihiala in Anambra State, Nigeria, and identified at the Department of Plant Science and Biotechnology, Imo State University, Owerri, Nigeria. A voucher specimen was deposited at the herbarium for further references.

\section{Extract preparation}

The leaves were thoroughly washed and dried in carbonated moisture extraction drying oven (Grand instruments, Cambridge, England) at $45{ }^{0} \mathrm{C}-50{ }^{0} \mathrm{C}$ for 3 hours. Grinding was done using Thomas contact Mills (Py Unicam, Cambridge, England), the powder was sieved through $1 \mathrm{~mm}$ sieve and $200 \mathrm{~g}$ was soaked in $1000 \mathrm{mls}$ of water and allowed to stand for 48 hours. The extract was filtered and the filtrate dried using hot air oven (Arrant instrument, Cambridge, England) at $45{ }^{0} \mathrm{C}-50{ }^{\circ} \mathrm{C}$. The residue yield was $52 \mathrm{~g}$ and appropriate concentrations made for the experimental design using distilled water (Nunomura et al., 2006).

\section{Paracetamol}

Paracetamol tablets (Emzor) were purchased from a registered pharmaceutical shop at Ihiala, Anambra State of Nigeria. The tablets were dissolved in distilled water (w/v) according to the required concentration for the administration on the Wistar rats based on body weight.

\section{Experimental animals}

Wistar rats weighing $150-250 \mathrm{~g}$ were procured from the Animal House of College of Medicine and Health Science, Imo State University, Owerri. They were maintained under controlled conditions of light (12/24 hours) and temperature. The animals were fed with standard pellet diet (product of Pfizer, Nigeria Ltd) and allowed free access to water ad libitum throughout the period of the experiment (Chattopadhyay and Bandyopadhyay, 2005). 


\section{Experimental design}

Forty wistar rats were used in this study and randomly divided into four groups of ten animals each (Table 1). Leaf extract, paracetamol and saline were administered with the aid of a feeding canular.

\section{Sample collection}

After 28 days of treatment, all the animals were weighed and sacrificed via euthanasia using chloroform after a 16 hours fast following the last administration. Blood was collected by cardiac puncture into heparinized tube, and centrifuged at 10,000 revolutions per minute for $5 \mathrm{~min}$ using Wisperfuge model 1384 (Tamson, Holland). Plasma was separated for various biochemical analysis and stored at $-20^{\circ} \mathrm{C}$ prior to use. The livers were dissected from all the animals, cleared of blood using normal saline and immediately transferred into blood ice-cold container of normal saline. The livers were homogenized in O.IN tris-HCL buffer (7.4) and used for the estimation of MDA, GPx and SOD (Challopadhyay and Bandyopadhyay, 2005).

\section{Acute toxicity testing}

The acute toxicity of $A$. indica aqueous leaf extract was done using 30 mice divided into 5 groups of 6 mice each. Each group received graded doses $(200-1000 \mathrm{mg} / \mathrm{kg}$ body weight) of the extract and the animals observed for toxic effects after 48 hours of treatment. The toxicological effect was observed in terms of mortality expressed as $\mathrm{LD}_{50}$. The number of animals that died during the period was noted. The $\mathrm{LD}_{50}$ of the extract was estimated from the graph of percentage (\%) mortality, converted to probity, against $\log$ - dose of the extract, probit 5 being $50 \%$ by Litch Field and Wilcoxon (Vaupel et al., 2005).

\section{Laboratory methods and procedures/ biochemical analysis}

The determination of AST and ALT was carried out using the Reitman and Frankel method (Nwaehujor et al., 2014) while ALT was measured by King and King method (Salman et al., 2016). Malondialydehyde (MDA) was determined by the method of Albro et al. (Dal-Pizzol et al., 2000 ). GPx was determined using the method of Paglia and Valentine, (Cichoski et al., 2012) while the method of Woolliams, et al., (Sarhan et al., 2014.) was used for SOD.

\section{Statistical analysis of data}

All values were expressed as mean \pm SD and then subjected to analysis of variance (ANOVA) using the Statistical Package for Social Sciences (SPSS) version 17.0 (SPSS Inc., Chicago Illinois). Statistical significance was considered at $\rho<0.05$.

Table 1: Experimental design showing the groups of Wistar rats and the treatments they were given.

\begin{tabular}{lc}
\hline Group & Treatment given \\
\hline A (Control) & Received only normal saline $(0.9 \% \mathrm{NaCl}$ w/v) $5 \mathrm{ml} / \mathrm{kg}$ body weight. \\
\hline $\mathrm{B}$ & Received only paracetamol $(800 \mathrm{mg} / \mathrm{kg}$ body weight) once daily. \\
\hline $\mathrm{C}$ & Received paracetamol $(800 \mathrm{mg} / \mathrm{kg}$ body weight) and $A$. indica leaves \\
& aqueous extract $(500 \mathrm{mg} / \mathrm{kg}$ bodyweight) once daily. \\
\hline $\mathrm{D}$ & Received paracetamol $(800 \mathrm{mg} / \mathrm{kg}$ body weight $)$ and $A$. indica leave \\
& aqueus extract $(1000 \mathrm{mg} / \mathrm{Kg}$ bodyweight $)$ daily. \\
\hline
\end{tabular}




\section{RESULTS}

Table 2 shows that there was a significant increase $(p<0.05)$ in the body weight of rats in groups $\mathrm{A}$ and $\mathrm{D}$, decrease in group $B$ and no significant change $(p<0.05)$ in the weights of Wister rats in group $\mathrm{C}$.

Table 3 shows that there was significant increase $(\mathrm{P}<0.05)$ in the plasma levels of the liver enzymes AST, ALT, and ALP in group B compared with group A. The plasma levels of AST and ALT in group C were significantly increased $(\mathrm{P}<0.05)$ compared with A. The plasma ALT level in group $\mathrm{C}$ was significantly increased when compared with A but no significant difference from group B. There was no significantly variation in plasma ALP level of group C from those of $\mathrm{A}$ and $\mathrm{B}$ rats. This table also shows that there was no significant difference in the plasma levels of AST, ALT and ALP in group D compared with A. But there was, however, significant decrease in plasma levels of AST, ALT and ALP in group D compared with group B. There was significant differences in plasma levels of AST and ALT between $\mathrm{C}$ and $\mathrm{D}$ but no significant difference in the plasma levels of ALP between groups C and D.

In Table 4, there was significant increase $(\mathrm{P}<0.05)$ in the plasma and liver homogenate levels of MDA in group $B$ rats compared with $\mathrm{A}$, while groups $\mathrm{C}$ and $\mathrm{D}$ showed no significant difference from $\mathrm{A}$. Groups $\mathrm{C}$ and D showed significant decrease compared with B. The plasma and homogenate GPx and SOD levels of group B are significantly decreased compared with A. This table also shows that homogenate GPx and SOD levels of group $\mathrm{C}$ and D showed significant increases compared with group B and significantly decreased compared with group A. Group D, though, significantly different in their homogenate GPx and SOD levels compared with $\mathrm{A}$, were significantly increased compared with group B. Significant decreased was observed in the plasma GPx and SOD levels in group B compared with group A. Plasma GPx and SOD in group D are significantly increased compared with group B but showed no significant difference from group A.

Table 2: Mean weight changes $(\mathrm{g})$ in Wister rats in various treatment groups $(\mathrm{A}-\mathrm{D})$.

\begin{tabular}{lccc}
\hline Group & Initial weight $(\mathbf{g})$ & Final weight $(\mathbf{g})$ & Change in weight $(\mathbf{g})$ \\
A & $167 \pm 8.4$ & $208 \pm 8.3$ & $41 \pm 6.2^{*}$ \\
B & $184 \pm 3.7$ & $175 \pm 4.4$ & $-9 \pm 3.1$ \\
C & $171 \pm 5.8$ & $177 \pm 5.6$ & $6 \pm 4.2$ \\
D & $194 \pm 5.8$ & $218 \pm 5.1$ & $24 \pm 4.1^{*}$ \\
\hline *Significantly different $(\mathrm{p}<0.05)$ from initial weight. & &
\end{tabular}

Table 3: Plasma levels of hepatic marker enzymes in various treatment groups (A - D)

\begin{tabular}{lccc}
\hline Groups & AST (u/l) & ALT (u/l) & ALP (u/l) \\
\hline A & $60.6 \pm 3.98$ & $62.8 \pm 3.25$ & $80.4 \pm 2.33$ \\
B & $106.2 \pm 2.56^{*}$ & $100 \pm 4.1^{*}$ & $89.2 \pm 3.12^{*}$ \\
C & $91.6 \pm 3.44^{* *}$ & $98.6 \pm 3.93^{*}$ & $86.2 \pm 2.71$ \\
D & $69.2 \pm 2.48^{* * *}$ & $65.6 \pm 2.8^{* * *}$ & $80.1 \pm 3.12^{* * *}$ \\
\hline
\end{tabular}

AST: Aspartate transaminase, ALT: Alanine transaminase, ALP: Alkaline phosphatase, ${ }^{*}$ Significantly different $(\mathrm{P}<0.05)$ from control group A.

** Significantly different $(\mathrm{P}<0.05)$ from groups $\mathrm{A}$ and $\mathrm{B}$

*** Significantly different $(\mathrm{P}<0.05)$ from group $\mathrm{B}$. 
Table 4: Plasma and liver homogenate MDA, GPx and SOD levels of in various treatment groups $(\mathrm{A}-\mathrm{D})$.

\begin{tabular}{lcccccc}
\hline \multirow{2}{*}{ Groups } & \multicolumn{2}{c}{ MDA } & \multicolumn{2}{c}{ GPx } & \multicolumn{2}{c}{ SOD } \\
\cline { 2 - 7 } & Homogenate & Plasma & Homogenate & Plasma & Homogenate & Plasma U/ml \\
& U/mg protein & nmol/ml & U/mg protein & U/ml & U/mg protein & \\
\hline A & $13.3 \pm 0.44$ & $3.51 \pm 0.16$ & $5.3 \pm 0.32$ & $3.4 \pm 0.24$ & $6.1 \pm 0.25$ & $8.7 \pm 0.36$ \\
$\mathrm{~B}$ & $24.1 \pm 0.22^{*}$ & $7.79 \pm 0.15^{*}$ & $2.9 \pm 0.25^{*}$ & $2.1 \pm 0.1^{*}$ & $2.5 \pm 0.32^{*}$ & $4.8 \pm 0.81^{*}$ \\
$\mathrm{C}$ & $13.6 \pm 0.22^{* * *}$ & $4.87 \pm 0.13$ & $4.1 \pm 0.3^{* * *}$ & $3.7 \pm 0.1^{* * *}$ & $4.6 \pm 0.3^{* *}$ & $6.6 \pm 0.27^{* *}$ \\
$\mathrm{D}$ & $12.7 \pm 0.21^{* * *}$ & $3.97 \pm 0.56^{* * *}$ & $5.0 \pm 0.28^{* * *}$ & $4.6 \pm .14^{* * *}$ & $5.9 \pm 0.28^{* *}$ & $8.1 \pm 0.28^{* * *}$ \\
\hline
\end{tabular}

MDA: Malondialdehyde, GPx: Glutathione peroxidase, SOD: Superoxide dismutase.

* Significantly different $(\mathrm{P}<0.05)$ from group A.

** Significantly different $(\mathrm{P}<0.05)$ from groups A and $\mathrm{B}$.

*** Significantly different $(\mathrm{P}<0.05)$ from group $\mathrm{B}$.

\section{DISCUSSION}

It appears that the overall effects of various treatments of the different groups used in this study were summarized in their respective weight changes presentation (Table 2). The significant weight loss in paracetamol treated Wister rats may be attributed to the negative biochemical effect engendered by the induced oxidative stress, while the no significant weight change observed in the ones treated with both paracetamol and $A$. indica aqueous leaf extract reflects the summary of the inhibitory effect of A. indica aqueous leaf on the oxidative stress.

The observed increase in the hepatic marker enzymes, AST, ALT and ALP, in paracetamol treated Wister rats (Table 3) agrees with its already documented hepatotoxic effect (Adeshina et al., 2011). And the no significant change demonstrated by these enzymes in the Wister rats treated with both paracetamol and A. indica extract is also similar to documented reports on hepatoprotective activity of $A$. indica (Chattopadhyay and Bandyopadhyay, 2005). This could be adduced to the antilipid peroxidative effect of the extract (Nwobodo, 2017), thereby maintaining the cell membrane integrity. The elevated levels of these hepatic enzymes in paracetamol treated Wister rats (group B) also agree with the alteration in the hepatocellular integrity. The significant increase in liver enzymes and MDA, which are indicators of oxidative stress and its resultant hepatotoxicity, in paracetamol intoxicated wister rats, as observed in this study, supports the concept that paracetamol over-dose is a precursor of pro-oxidants, which mediate oxidative stress and cell death as reported by Gujral et al. (2002). The mild but significant effect on ALP may mean that though paracetamol intoxication causes hepatocellular damage (Hazai et al., 2002), cholestasis may not be primarily involved.

The lipid peroxidation product (MDA) level was increased in paracetamol treated Wister rats while the antioxidant enzymes GPx and SOD were depleted. This finding is consistent with the previous works reported by Yanpallewar et al. (2003). The increase in MDA implies increased lipid peroxidation as a result of oxidative stress which could have been induced by paracetamol, as shown in Table 4. The no significant change in MDA of groups $\mathrm{C}$ and D compared with control (group A) animals, and the significant decrease when compared with group B animal, may mean that $A$. indica aqueous leaf extract can offer protection against paracetamol induced free radical injury and thus could be a good antidote to oxidative stress and its resultant cell death (hepatotoxicity). 
The decrease in antioxidant enzymes (GPx and SOD) activities with elevated MDA level could probably be associated with oxidative stress and, or decreased antioxidant potential. The decrease in SOD in group B animals may also be attributed to enhanced superoxide production resulting to the mopping up of the available SOD. In the animals treated with both paracetamol and $A$. indica aqueous leaf extract, there was no significant increase in MDA while GPx and SOD were remarkably increased. This may imply that the oxidative stress induced by paracetamol was almost completely obliterated by the concommittant administration of $A$. indica aqueous leaf extract.

Consequently, the observed variations in the elevated or reduced levels of biochemical parameters evaluated in this work, with regards to varied doses of $A$. indica extract used, could suggest that its effect in controlling oxidative stress, hence hepatotoxicity, may be dose-dependent.

\section{Conclusion}

Based on the fndngs in this study, it could be inferred that $A$. indica aqueous leaf etract could enhance enzymatic antioxidants and consequently has hepatoprotective effects on paracetamol-treated Wister rats. Considerably, having observed the invaluable role A. indica could play in attenuating or obliterating oxidative stress conditions including hepatocellular damage, it is recommended that further studies be carried out to elucidate the molecular basis of both the biochemical and pharmacological involvement of this extract in achieving this.

\section{COMPETING INTERESTS}

The authors declare that they have no competing interests.

\section{AUTHORS' CONTRIBUTIONS}

EIN conceptualised and designed the study, and participated in statistical analysis and manuscript drafting. DCN revised the manuscript for intellectual content and approved it. SOO and FOU participated in manuscript drafting, data acquisition (laboratory work) and interpretation. ACI did the animals recruitment and handling, sample collection and participated in data acquisition and interpretation. NOA did the literature search and participated in statistical analysis. JKN and OA participated in statistical analysis and manuscript drafting. All authors read and approved the final manuscript.

\section{ACKNOWLEDGMENTS}

The authors acknowledge Professor Harrison Nwanjo, Department of Medical Laboratory Sciences, Imo State University Owerri, for his contribution in the successful completion of this study. Also appreciated is Dr. Chukwuemeka Ohagwu, Department of Radiography, Nnamdi Azikiwe University, Awka, Nigeria whose encouragement contributed to the successful completion of this manuscript.

\section{REFERENCES}

Adeyemi OS, Akanji MA. 2011. Biochemical changes in the kidney and liver of rats following administration of ethanolic extract of Psidium guajava leaves. Human and Experimental Toxicology, 30(9): $\quad 1266-1274 . \quad$ DOI: sagepub.com/doi/abs/10.1177/09603271 10388534.

Adeshina AJ, Fakunle PB, Oloyede AO. 2011. Some Protective Effects of Aqueous Leaf Extract of Azadirachta indica on Paracetamol-induced Hepatotoxicity in Adult Wistar Rats. American Journal of Tropical Medicine \& Public Health, 1(3): 97-106.

Bhanwra S, Singh P, Koshla P. 2000. The effect of Azadirachta indica (Neem) 
leaf aqueous extract on paracetamol induced liver damage in rats. Ind. $J$. Physiol. Pharmacol., 44: 64-69.

Brooks M, Hybertson Bifeng Gao, Swapan K, Bose Joe MM. 2011. Oxidative stress in health and disease: The therapeutic potential of Nrf2 Activation. Molecular Aspects of Medicine, 32: 234-246. DOI: https://doi.org/10.1016/j.mam.2011.10.0 06.

Chandra K, Syed SA, Abid M, Sweety R, Najam AK. 2015. Protection Against FCA Induced Oxidative Stress Induced DNA Damage as a Model of Arthritis and In vitro Anti-arthritic Potential of Costus speciosus Rhizome Extract. Int. J. Pharmacog. Phytochem. Res., 7(2): 383 - 389.

Chattopadhyay RR, Bandyopadhyay M. 2005. Effect of Azadirachta indica leaf extract on serum lipid profile changes in normal and streptozotocin induced diabetic rats. African J. Biomed. Res., 8(2):101 - 104.

Cichoski AJ, Rotta RB, Scheuerman G., Cunha Junior A, Barin JS. 2012. Investigation of glutathione peroxidase activity in chicken meat under different experimental conditions. Ciênc. Tecnol. Aliment., Campinas, 32(4): 661-667. http://dx.doi.org/10.1590/S010120612012.

Dal-Pizzol F, Klamt F, Vianna MMR, Schröder N, Quevedo J, Benfato MS, Moreira JCF, Walz R. 2000. Lipid peroxidation in hippocampus early and late after status epilepticus induced by pilocarpine or kainic acid in Wistar rats. Neuroscience Letters, 291(3):179-182. DOI: https://doi.org/10.1016/S03043940(00)01409-9.

David AO, Benedict AF, Adebimpe EO, Eze kiel AC. 2010. Regenerative potential of aqueous extract of Neem (Azadirachta indica) on the stomach and ileum following ethanol induced mucosal lesion in adult wister rats. $J$. Gastroenterology Res., 3(2): 86-90.

Ehiaghe FA. 2015. Some physiochemical changes associated with type 2 diabetes mellitus in Benin City, Nigeria. Int. J. Biol. Chem. Sci., 9(5): 2582 - 2588, DOI: http://dx.doi.org/10.4314/ijbcs.v9i5.27.

El-Hawary SS, El-Tantawy ME, Rabeh MA, Badr WK. 2013. Chemical composition and biological activities of essential oils of Azadirachta indica. A. Juss, International Journal of Applied Research in Natural Products, 6: 33-42.

Fakher SH, Djalali M, Tabei SMB, Zeraati H, Javadi E, Sadeghi MR, Mostafavi E, Fatehi F. 2007. Effect of Vitamins A, E, $\mathrm{C}$ and Omega-3 Fatty Acids on Lipid Peroxidation in Streptozotocin Induced Diabetic Rat. Iranian J. Publ. Healt., 36(2): 58-63.

Gujral JS, Knight TR, Farhood AP, Bajt ML. 2002. Mode of cell death after acetaminophen over-dose in mice: apaptosis or oncotic necrosis. Toxicological Science, 67: 322 - 328.

Hazai E, Vereczkey L, Monostory K. 2002. Reduction of toxic metabolites formation of acetaminophen. Bioch. Brophys. Res. Ommun., 291(4): 1089-1094. DOI: 10.1006/bbrc.2002.6541.

Hossain MA, Al-Toubi WAS, Weli AM, AlRiyami QA, Al-Sabahi JN. 2013. Identification and characterization of chemical compounds in different crude extracts from leaves of Omani neem. $J$. Taibah Univ. Sci., 7(4): 181 - 188. https://doi.org/10.1016/j.jtusci.2013.05.0 03.

Hye-Lin H, Hye-Jun S, Mark AF, Dae-Yeul Y. 2010. Oxidative stress and antioxidants in pathogenesis. World $J$ gastroenterol., 16(48): 6035 - 6043. Johnson F, Giulivi C. 2005. Superoxide dismutases and their impact upon human health. Molecular Aspects of Medicine, 26(4-5): 340-52. 
Kausik B, Ishita C, Ranajit KB, Uday B. 2002. Biological Activities and Medicinal Properties of Neem (Azadirachta indica). Current Sci., 82(11): 1336-1345.

Kokate C, Purohit AP, Gokhale SB. 2010. Pharmacognosy. Nirali Prakashan India, 10: 28-29.

Kpemissi M, Metowogo K, Lawson-Evi P, Eklu-Kadégbékou K, Aklikokou AK, Gbéassor M. 2015. Hepatoprotective and antioxidant effects of Acanthospermum hispidum (DC) leaves on carbon tetrachloride-induced acute liver damage in rat. Int. J. Biol. Chem. Sci., 9(5): 2263 $-2271$. DOI http://dx.doi.org/10.4314/ijbcs.v9i5.1.

Momoh J, Longe AO, Damazio OA, Eleyowo OO. 2015. Hepatoprotective Effect of Ethanolic Leaf Extract of Vernonia amygdalina and Azadirachta indica against Acetaminophen-Induced Hepatotoxicity in Sprague-Dawley Male Albino Rats. Am. J. Pharmacol. Sci., 3(3): 79-86. DOI: 10.12691/ajps-3-3-5.

Niedworok E, Bielaszka A. 2007. Comparison of the effect of vitamins $\mathrm{A}$ and $\mathrm{E}$ on Aging processes of edible vegetable oils. Polish J. Environ. Stud., 16(6): 861-865.

Nunomura A, Castellani RJ, Zhu X, Moreira PI, Perry G, Smith MA. 2006. Involvement of oxidative stress in Alzheimer disease. Journal of Neuropathology and Exp. Neurol., 65(7):631-41. DOI: 10.1097/01.jnen. 0000228136.58062.bf.

Nwaehujor CO, Eban LK, Ode JO, Ejiofor CE, Igile GO. 2014. Hepatotoxicity of Methanol Seed Extract of Aframomum melegueta [Roscoe] K. Schum. (Grains of paradise) in Sprague-Dawley Rats. Am. J. of Biomed Res., 2(4): 61 - 66. DOI: 10.12691/ajbr-2-4-1.

Nwobodo EI. 2017. Evaluation of Antilipid Peroxidation and Hypolipidemic Potentials of Azadirachta indica Leaf
Aqueous Extract in Paracetamol Induced Hepatotoxicity in Wistar Rats. Int. J. Inform. Res. Rev., 4(2): 3615-3619. https://doi.org/10.5897/JMPR2015.6026.

Prashanth GK, Krishnaiah GM. 2014. Chemical composition of the leaves of Azadirachta Indica Linn (Neem). Int. J. Adv. Eng. Tech. Manag. and Appl. Sci. 1(5): 21-31.

Rhee SG, Chae HZ, Kim K 2005. Peroxiredoxins: a historical overview and speculative preview of novel mechanisms and emerging concepts in cell signaling. Free Radic. Biol. Med., 38(12): 1543-52. DOI: $10.1016 / \mathrm{j}$. freeradbiomed.2005.02.026.

Roušar $\mathrm{T}$, Kučera $\mathrm{O}$, Křiváková $\mathrm{P}$, Lotková H, Kand'ár R, Mužáková V, Červinková Z. 2009. Evaluation of Oxidative Status in Acetaminophen-Treated Rat Hepatocytes in Culture. Physiol. Res., 58: $239-246$.

Salman MMA. Kotb AM, Haridy MAM, Hammad S. 2016. Hepato- and nephroprotective effects of bradykinin potentiating factor from scorpion (Buthus occitanus) venom on mercuric chloride-treated rats. EXCLI J. 15: 807816. DOI: 10.17179/excli2016-777.

Sarhan MAA, Shati AA, Elsaid FG. 2014. Biochemical and molecular studies on the possible influence of the Brassica oleracea and Beta vulgaris extracts to mitigate the effect of food preservatives and food chemical colorants on albino rats. Saudi Journal of Biological Sciences, 21(4): 342-354 https://doi.org/ 10.1016/j.sjbs.2013.11.004.

Suja SR, Latha PG, Pushpangadan P, Rajasekharan S. 2004. Evaluation of hepatoprotective effects of Helminthostachys zeylanica hook against carbon tetrachloride-induced liver damage in wistar rats. Journal of Ethnopharmacology, 92: 61-66. 
Vaupel DB, Tella SR, Huso DL, Wagner VO, Mukhin AG, Chefer SI, Horti AG, London ED, Koren AO, Kimes AS. 2005. Pharmacological and Toxicological Evaluation of 2-Fluoro-3(2(S)-azetidinylmethoxy)pyridine (2-FA-85380), a Ligand for Imaging Cerebral Nicotinic Acetylcholine Receptors with Positron Emission Tomography. J. Pharmacol. Exp. Therap., $\quad 312(1)$ : 355-365. DOI:https://doi.org/10.1124/jpet.104.073 999.

Vemo BN, Kenfack A, Ngoula F, Akono Nantia E, Kodjio N, Nounamo Guiekep AJ, Megnimea Tsambou AM, Teguia A. 2017. Effects of ethanol extract of Bersama engleriana leaves on oxidative stress and reproductive parameters in male Guinea pig (Cavia porcellus) exposed to cypermethrin. Int. J. Biol. Chem. Sci., 11(5): 2243-2253. DOI: http://dx.doi.org/10.4314/ijbcs.v11i5.23.
Vitaglione P, Morisco F, Caporaso N, Fogliano V. 2004 Dietary antioxidant compounds and liver health. Crit. Rev. Food Sci. Nutr., 44: 575-586.

Willcox JK, Ash SL, Catignani GL. 2004. Antioxidants and prevention of chronic diseases. Crit. Rev. Food Sci. Nutr., 44(4): 275-295. DOI: 10.1080/10408690490468489 .

Yanpallewar SU, Sen S, Kumar M, Raju SS, Achary SB. 2003. Effect of Azadirachta indica on paracetamol induced hepatic damage in albino rat. Phytomedicine, 10: 391-396.

Zelko IN, Mariani TJ, Folz RJ. 2002. Superoxide dismutase multigene family: a comparison of the CuZn-SOD (SOD1), Mn-SOD (SOD2), and ECSOD (SOD3) gene structures, evolution, and expression. Free Radic. Biol. Med., 33(3): 337-349. DOI:10.1016/S08915849(02)00905-X. PMID 12126755. 